\title{
Factors associated with delay in care-seeking for fatal neonatal illness in the Sylhet district of Bangladesh: results from a verbal and social autopsy study
}

Bareng AS Nonyane ${ }^{1,2}$, Narjis Kazmi ${ }^{1}$, Alain K Koffi ${ }^{1}$, Nazma Begum², Salahuddin Ahmed ${ }^{2}$, Abdullah H Baquil $^{1,2}$, Henry D Kalter ${ }^{1}$

\footnotetext{
${ }^{1}$ Department of International Health, Johns Hopkins Bloomberg School of Public Health, Baltimore, MD, USA

${ }^{2}$ International Center for Maternal and Newborn Health, Johns Hopkins Bloomberg School of Public Health, Baltimore, MD, USA
}

Background We conducted a social and verbal autopsy study to determine cultural-, social-and health system-related factors that were associated with the delay in formal care seeking in Sylhet district, Bangladesh.

Methods Verbal and social autopsy interviews were conducted with mothers who experienced a neonatal death between October 2007 and May 2011. We fitted a semi-parametric regression model of the cumulative incidence of seeking formal care first, accounting for competing events of death or seeking informal care first.

Results Three hundred and thirty-one neonatal deaths were included in the analysis and of these, 91(27.5\%) sought formal care first; $26(7.9 \%)$ sought informal care first; 59 (17.8\%) sought informal care only, and 155 (46.8\%) did not seek any type of care. There was lower cumulative incidence of seeking formal care first for preterm neonates (sub-hazard ratio SHR 0.61, P=0.025), and those who delivered at home (SHR 0.52, P=0.010); and higher cumulative incidence for those who reported less than normal activity (SHR 1.95, $P=0.048$ ). The main barriers to seeking formal care reported by 165 mothers included cost $(n=98,59.4 \%)$, believing the neonate was going to die anyway $(n=29,17.7 \%)$, and believing traditional care was more appropriate $(n=26,15.8 \%)$.

Conclusions The majority of neonates died before formal care could be sought, but formal care was more likely to be sought than informal care. There were economic and social belief barriers to careseeking. There is a need for programs that educate caregivers about well-recognized danger signs requiring timely care-seeking, particularly for preterm neonates and those who deliver at home.

\section{Correspondence to:}

Bareng Nonyane

Department of International Health

Johns Hopkins Bloomberg School of Public

Health

$615 \mathrm{~N}$ Wolfe Street

21205 Baltimore ML

USA

bnonyan1@jhu.edu
Recent estimates show that 6.3 million children died in 2013, which is a decline from 12.7 million in 1990 [1]. Of these 6.3 million, 2.8 million babies died in the neonatal period (within 28 days of birth) making up $44 \%$ of all under 5 deaths, a trend that has been observed over the last two to three decades [2-4]. Most of the under-5 deaths occur in developing countries where the estimated rate in 2012 was 53 per 1000 live births $(90 \%$ uncertainty bound 51,56$)$ compared to $6(6,7)$ per 1000 live births in developed countries [5]. Most of the deaths in developing coun- 
tries occur due to preventable causes for which care could be made available by targeted interventions [6]. Liu et al [7] estimated that in 2013, 2.761 million (44\%) of the under -5 deaths were in the neonatal period, and among those 0.42 million neonates died of sepsis. Appropriate and timely care-seeking for infections could substantially improve neonatal survival. A systematic review of care-seeking behaviors for neonatal and childhood illnesses in low and middle-income countries showed that levels of care-seeking vary considerably by geographic region, with levels in South Asia being particularly low [8].

\section{Delays in care-seeking and constraining factors}

Care-seeking by itself is important, but even more important is the ability to reach out to available qualified health care providers as soon as the illness signs are recognized. The 3-delays model for care-seeking for maternal illnesses was developed by Thadeus and Maine (1994) [9] and has been applied to characterize the delay in seeking care for childhood illnesses [10-14]. This model identifies the delay in 1) recognizing danger signs and deciding to seek care, 2) time to get to the health facility and 3) receiving adequate and appropriate care after reaching the facility.

Traditional beliefs and cultural practices have been shown to influence decision-making and the time to seeking care [15-19]. A specific example is that in Rajasthan, India, care-seeking for sick neonates was found to be less than that for older infants and children, mainly due to caretakers believing that even qualified providers lack the expertise to treat newborns [16-18]. Qualitative research in three South Asian countries (Bangladesh, Nepal and Pakistan) found that local traditions, lack of knowledge about the importance of care-seeking and recognition of danger signs and perceived poor quality of health services were important factors [19]. A focused ethnographic study in India found that despite caretakers recognizing danger signs indicating that their child needed health care, inability to discriminate among the available health care sources and perceived poor quality of health services led them to delay seeking care or to seek care from unqualified providers [20].

Similar results have been found in Sub-Saharan Africa and Latin America. For example, in some cases, caregivers assume that they know what the illness is and treat it at home instead of seeking formal care [12]. Other influences include lack of knowledge about dangerous illness symptoms [21], and various factors that ranged from social and traditional beliefs as well as poor health systems [10,11,22-25].

\section{Care-seeking in Bangladesh}

Bangladesh has a total population of 160 million and 9.6\% of the population is under 5 years of age. The Bangladesh
Demographic and Health Survey shows that the country had an under-5 mortality rate of 53 per 1000 live births and neonatal mortality rate of 32 per 1000 live births in 2011 [26]. Even though the country has met the Millennium Development Goal (MDG) 4 of reducing child mortality by two-thirds between 1990 and 2015, the neonatal mortality rate is still high and it requires targeted interventions to promote timely care-seeking for neonatal illness.

In a study done in rural Bangladesh to assess the careseeking patterns for neonatal morbidity, it was seen that although most of the mothers sought outside care, only a small percentage of those who sought care considered going to a qualified provider and that was true even for the neonatal mortalities [27]. A recent study in Mirzapur Bangladesh found that even for older children (1-59 months) caretakers prefer to visit unqualified providers or other sources as compared to a formal provider [28]. Another study from Sylhet Bangladesh showed that preventative or curative care was sought for only $30.9 \%$ of preterm newborns from qualified providers [29]. A study by Chowdhury et al. [30] in Matlab, Bangladesh found that 37\% of 365 neonates who had a fatal illness had formal care sought for them while the rest either received traditional or no care. The authors highlighted the need to design programs that take into consideration the use of traditional care and formal care in order to promote timely careseeking.

\section{Verbal and Social Autopsy studies to study care-seeking behavior}

In low- and middle-income countries (LMICs), death registries are often either poorly kept or non-existent and, as a result, verbal autopsies (VAs) are used to help determine the likely cause of death. These are questionnaire instruments that are used to collect reported illness symptoms and information on pregnancy and intra-partum complications, in the case of neonates. The data are then used to determine the likely cause of death using physician assessments or expert algorithms [31-35]. Social autopsies (SAs) are conducted to help determine social and health system factors associated with care-seeking behavior $[36,37]$.

There is very limited literature on comparative studies of those who seek formal care vs those who do not, and the factors associated with that decision $[8,38]$. In this study, we used data from a verbal and social autopsy (VASA) study in the Sylhet district of Bangladesh. We conducted an exploratory analysis to determine the illness symptoms as well as social and demographic factors that were associated with the delay in seeking formal care for a neonatal illness that led to death. Our analysis accounted for the competing risks of death and seeking informal care before formal care could be sought. 


\section{METHODS}

\section{Setting and participants}

The VASA survey data were collected from four unions of Zakiganj sub-district with an estimated population of 102 000; and four unions of Kanaighat sub-district with an estimated population of 100000 in the Sylhet district of Bangladesh. Initially, data were collected with a 1 year recall period, and this was extended for up to 2.5 years in order to attempt to achieve the desired sample size of up to 500 neonatal deaths. This sample size was determined for estimating the cause of death distribution (the first objective of the study) with 5\% precision for the main common causes of death. The current-study's objective (delay in care-seeking) utilized a subset of these neonatal deaths that fitted the inclusion criteria. Babies born to ever-married mothers of child-bearing age ( 15 to 49 years old) were included. Deaths that occurred between October 2007 and May 2011 were included. Respondents were selected among participants of other studies on community-based interventions for maternal and newborn care. These were the Healthy Fertility study, which was aimed at improving healthy birth-spacing [39], and the Chlorhexidine trial which was a three-arm trial comparing the effect of umbilical cord cleansing with chlorhexidine once, over a 7day period, and the control arm which was dry cord-care $[39,40]$. The verbal autopsy questionnaires were administered retrospectively by trained female data collectors. Social autopsy interviews were conducted by trained female interviewers. Mothers who had had multiple deaths were interviewed for each of the deaths separately. The questionnaires used were the World Health Organization's (WHO) standard verbal autopsy tool [41] and the WHO/UNICEFsupported Child Health Epidemiology Reference Group (CHERG) social autopsy tool $[36,42]$.

\section{Analysis}

The main event of interest was the time to seeking formal care, reported in days since illness onset. Illness onset was defined as the time when the first symptoms were recognized. Formal care in this context was defined as care provided by one of the following: a trained community health worker (CHW), private doctor or NGO/Government health center/post or hospital. Informal care was defined as seeking care from a traditional healer or from a pharmacist/drug seller. Other than the main outcome of seeking formal care, there were other possible events that may have taken place before formal care was sought and they were important to consider because they could have altered the probability of seeking formal care. These were a) death before any care was sought (survival bias) and b) seeking informal care first or only, and they were referred to as competing risk events
[43]. Failure to account for these competing events (that is treating them as censoring events) may lead to an over-estimation of the incidence of seeking formal care and the effect estimates of the potential predictors. We calculated and plotted the cumulative incidence functions (the probability of an event of type $k$ before or up to time $t$ ) for each of the possible events [44].

We then built a semiparametric regression model to estimate the cumulative incidence of seeking formal care first in the presence of competing events, and we report corresponding sub-hazard ratios (SHRs) with respect to each predictor $[45,46]$. The effect estimate is referred to as a 'sub-hazard' ratio because it pertains to one event among all possible events in any given time point. This model is analogous to the Cox proportional hazards model except that hazard ratios for an event $k$ (such as seeking formal care) are calculated conditional on an individual having had no other event up to time $t$. SHRs are interpreted as a reduction or increase in cumulative incidence of an event. Unadjusted regression models were fitted for each potential predictor separately, and the predictors with a $P$-value $\leq 0.2$ were included in the multivariable model. We investigated possible multi-collinearity among some of the predictors and its effect on the interpretation of the results.

A subset of the mothers who had not taken their neonate to a formal health care provider said that they had 'concerns' that prevented them from doing so. A subset of those who had sought formal care said they had 'concerns' that they had to overcome in doing so. Furthermore, those mothers who reported that their neonates died immediately were never asked about any concerns they had. These concerns were potential barriers to care-seeking and since they were not applicable or answered by all respondents, they were not included in the main regression analysis and only summary statistics of these are given.

\section{Inclusion/exclusion}

In order to assess care-seeking from home, only participants whose baby was either born at home, or left the delivery facility alive, were included in the analysis.

\section{Potential predictors}

We considered the following classes of predictors as shown in Table 1: neonate's demographic factors, neonatal care variables, illness symptoms, mother's/father's factors, household factors, social and health system factors. We used the WHO's Integrated Management of Childhood Illnesses (IMCI) severity grading for the first symptoms they observed. For the illness symptoms that were in the VA instrument but not in the IMCI, two physician authors (HDK, AKK) assigned symptoms as severe (requiring referral to higher level formal care) or possibly severe (requiring for- 
Table 1. Potential predictors for care-seeking behavior

\begin{tabular}{|c|c|}
\hline FAстоR & VARIABLE \\
\hline Neonate's demographic factors & $\begin{array}{l}\text { - Age of neonate at illness onset (days) } \\
\text { - Gender }\end{array}$ \\
\hline $\begin{array}{l}\text { Neonates care, illness } \\
\text { symptoms/conditions }\end{array}$ & $\begin{array}{l}\text { - Neonate ever breastfed? } \\
\text { - Whether the newborn received any liquids or solids other than breast milk (exclusive breastfeeding); } \\
\text { - Severity of the observed first symptoms for which care was reportedly sought } \\
\text { - Birth size of the baby } \\
\text { - Whether the neonate was preterm or not } \\
\text { - Whether the baby had any malformation at birth } \\
\text { - Mother/care-giver's perception of the status at illness onset: } \\
\text { - feeding status (feeding normally, poorly or not at all) } \\
\text { - activity (normally active, less active than normal or not moving) }\end{array}$ \\
\hline Mother/father's factors & $\begin{array}{l}\text { - Mother's age } \\
\text { - Mother's education } \\
\text { - Father's education } \\
\text { - Whether the mother sought any antenatal care at a health provider } \\
\text { - Whether mother had any pre-pregnancy medical condition }\end{array}$ \\
\hline Household factors & $\begin{array}{l}\text { - Whether mother was the household breadwinner } \\
\text { - Where the mother stayed during the last days of her pregnancy }\end{array}$ \\
\hline Specific barriers & $\begin{array}{l}\text { - Any specific concerns or problems caregiver had: Thought baby not sick enough; no one available to go with care- } \\
\text { giver; too much time from regular duties; someone else had to decide; too far to travel; no transportation available; } \\
\text { cost; not satisfied with available health care; problem required traditional care; thought too sick to travel; thought } \\
\text { child will die anyway; it was late at night; no transport/provider; other }\end{array}$ \\
\hline Health system factors & $\begin{array}{l}\text { - Delivery place } \\
\text { - Time in minutes to usual health provider }\end{array}$ \\
\hline
\end{tabular}

mal health care). The listing of the symptoms and their severity scoring are given in Online Supplementary Document.

\section{Ethical considerations}

The VASA study was approved by the Institutional Review Boards of the Johns Hopkins University and the Bangladesh Medical Research Council. All respondents provided informed consent before being interviewed.

\section{RESULTS}

A total of 378 death records were available for analysis. Of these, 46 died at the facility in which they were born and thus, per inclusion/exclusion criteria, were excluded from the analysis; one had an unknown place of birth; and the rest $(n=331)$ were included in the analysis. The 331 comprised 307 babies born at home and 24 born at a facility and discharged alive. Furthermore, 12 of these mothers had given interviews about 2 deaths each. The recall period was 1 year in the initial study plan and under this criterion $72.5 \%$ (240/331) of the verbal autopsies were conducted. As the recall period was extended to 2.5 years in order to increase sample size, an additional 27.5\% (91/331) VAs were conducted.

Table 2 shows some basic characteristics of these 331 participants and the types of care sought for them. The outcome of interest was seeking formal care first; and this was done for 91 (27.5\%) neonates while 26 (7.9\%) sought informal care before seeking formal care. Informal care only was sought for 59 (17.8\%) neonates and 155 (46.8\%) died before any care could be sought for them. The cumulative incidence functions for each of these competing events are given in Figure 1. These show that dying without any care sought was the most likely outcome, followed by seeking formal care first and seeking informal care only, while seeking informal care first was the least likely event.

The results of the unadjusted regression analysis for each potential predictor are given in Table 3 , and the predictors with a $P$-value $\leq 0.2$ were included in the multivariable model. The results from the multivariable model (Table 4)

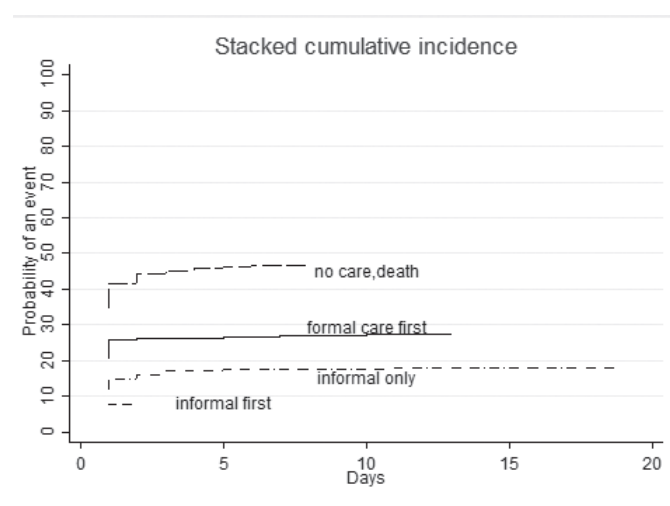

Figure 1. Cumulative incidence plots. 
Table 2. Baseline characteristics of participants and care-seeking behavior

\begin{tabular}{|c|c|c|c|}
\hline Variable & $N=331$ & $\%$ & $\begin{array}{c}\text { Median } \\
\text { (INTERQuartille range) }\end{array}$ \\
\hline Neonate's gender $=$ female & 147 & 44.4 & \\
\hline Age (days) at illness onset & & & $0(0,2)$ \\
\hline Place of birth=hospital/facility & 25 & 7.5 & \\
\hline Formal care sought first & 91 & 27.5 & \\
\hline Informal care sought first & 26 & 7.9 & \\
\hline Informal care only sought & 59 & 17.8 & \\
\hline No care sought & 155 & 46.8 & \\
\hline $\begin{array}{l}\text { Median time (day of illness) to } \\
\text { first seeking formal care }\end{array}$ & & & $1(1,2)$ \\
\hline $\begin{array}{l}\text { Median time (days) from illness } \\
\text { onset to death }\end{array}$ & & & $1(0,2)$ \\
\hline $\begin{array}{l}\text { Median time(days) to informal } \\
\text { care-seeking }\end{array}$ & & & $1(1,2)$ \\
\hline
\end{tabular}

show that there was a lower cumulative incidence of seeking care for preterm vs full-term neonates $(\mathrm{SHR}=0.61$, $P=0.025)$ and those who delivered at home $(\mathrm{SHR}=0.52$, $P<0.010)$. Those who reported less than normal activity in a neonate were more likely to seek formal care than those who reported normal activity $(\mathrm{SHR}=1.95, P=0.025)$.
Table 5 shows the summary data on the barriers to seeking care raised by respondents. A subset of 165 mothers reported having these concerns or barriers, and among those, 39 had taken their neonates to seek formal care despite the barriers. The most common barrier was cost, which was raised by 98 (60\%) of the mothers, 67 of whom had not sought formal care. The next common barriers were: thinking that the baby would die anyway $(n=29$, $18 \%)$, thinking the baby needed traditional care $(n=26$, $16 \%)$, being too late at night to travel $(n=19,12 \%)$, and the distance to the formal care facility $(\mathrm{n}=18,11 \%)$.

\section{DISCUSSION}

Care-seeking for neonatal and child illnesses in resourcelimited settings is low. In this study, we aimed to determine factors associated with care-seeking behavior for fatal neonatal illness in Sylhet, Bangladesh, using data from verbal and social autopsy questionnaires. Our main outcome of interest was time to the first instance of seeking formal care. In order to conduct such an analysis, it was crucial to condition, at each time point during follow-up, on the neonate

Table 3. Characteristics of the sample and results of unadjusted regressions for the time in days to first instance of seeking formal care

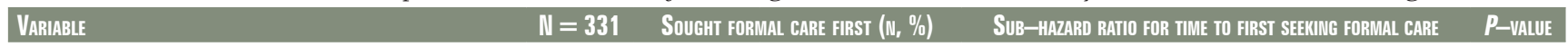
Age at illness onset-days:

\begin{tabular}{|c|c|c|c|c|}
\hline 0 & 216 & $58(26.9)$ & 1 & \\
\hline $1-3$ & 26 & $8(30.8)$ & 1.2 & 0.64 \\
\hline $3+$ & 87 & $24(27.6)$ & 1.1 & 0.8 \\
\hline Missing & 2 & & & \\
\hline \multicolumn{5}{|l|}{ Gender: } \\
\hline Male & 184 & $57(30.9)$ & 1 & \\
\hline Female & 147 & $34(23.1)$ & 0.7 & 0.09 \\
\hline \multicolumn{5}{|l|}{ Newborn ever breastfed: } \\
\hline No & 170 & $38(22.4)$ & 1 & \\
\hline Yes & 160 & $53(33.3)$ & 1.5 & 0.03 \\
\hline Don't know & 1 & & & \\
\hline \multicolumn{5}{|c|}{ Were first symptoms observed severe/possibly severe? } \\
\hline No & 19 & $1(20.3)$ & 1 & \\
\hline Yes & 267 & $78(29.2)$ & 2.74 & 0.15 \\
\hline \multicolumn{5}{|l|}{ Birth size: } \\
\hline Very small/smaller than usual & 214 & $58(27.1)$ & 1 & \\
\hline Average/larger than usual & 117 & $33(28.2)$ & 0.99 & 0.96 \\
\hline \multicolumn{5}{|l|}{ Preterm birth: } \\
\hline No & 227 & $69(30.4)$ & 1 & \\
\hline Yes & 103 & $22(21.4)$ & 0.66 & 0.08 \\
\hline Don't know & 1 & & & \\
\hline \multicolumn{5}{|l|}{ Malformation at birth: } \\
\hline No & 325 & $89(27.4)$ & 1 & \\
\hline Yes & 6 & $2(33.3)$ & 1.2 & 0.81 \\
\hline \multicolumn{5}{|c|}{ Feeding status at illness onset: } \\
\hline Normal & 43 & $11(25.6)$ & 1 & \\
\hline Poorly & 109 & $41(37.6)$ & 1.5 & 0.21 \\
\hline Not at all & 178 & $39(21.9)$ & 0.83 & 0.56 \\
\hline \multicolumn{5}{|c|}{ Activity status at illness onset: } \\
\hline Normally active & 53 & $10(18.9)$ & 1 & \\
\hline Less active than normal & 182 & $64(35.2)$ & 1.9 & 0.04 \\
\hline Not moving & 94 & $17(18.1)$ & 0.95 & 0.83 \\
\hline Missing & 2 & 0 & & \\
\hline \multicolumn{5}{|l|}{ Mother's age: } \\
\hline 18-20years & 52 & $18(34.6)$ & 1 & \\
\hline 21-25years & 110 & $36(32.7)$ & 0.88 & 0.61 \\
\hline
\end{tabular}


Table 5. Specific concerns/problems that were barriers to formal care-seeking-reported by mothers

\begin{tabular}{|c|c|c|c|}
\hline & TотAL $(\mathbb{N}=165)$ & $\begin{array}{l}\text { Total N }=39 \\
\text { (OF } 165) \text { SOUGHT } \\
\text { FORMAL CARE }\end{array}$ & $\begin{array}{c}\text { TOTAL N = } 126 \text { (OF } \\
165 \text { ) WHO DID NOT } \\
\text { SEEK FORMAL CARE }\end{array}$ \\
\hline & $\mathrm{n}(\%)$ & $\mathrm{n}(\%)$ & $\mathrm{n}(\%)$ \\
\hline \multicolumn{4}{|c|}{ Mother's specific concern - thought not sick enough: } \\
\hline No & $151(91.5)$ & $39(100)$ & $112(88.9)$ \\
\hline Yes & $14(8.5)$ & 0 & $14(11.1)$ \\
\hline \multicolumn{4}{|c|}{ Mother's specific concern - no one available to go with her: } \\
\hline No & $157(95.2)$ & $39(100)$ & $118(93.7)$ \\
\hline Yes & $8(4.8)$ & 0 & $(6.3)$ \\
\hline \multicolumn{4}{|c|}{ Mother's specific concern - cost: } \\
\hline No & $67(40.6)$ & $6(15.4)$ & $61(48.4)$ \\
\hline Yes & $98(59.4)$ & $33(84.6)$ & $65(51.6)$ \\
\hline \multicolumn{4}{|c|}{ Mother's specific concern - too much time from regular duties: } \\
\hline No & $148(89.7)$ & $38(97.4)$ & $110(87.3)$ \\
\hline Yes & $17(10.3)$ & $1(2.6)$ & $16(12.7)$ \\
\hline \multicolumn{4}{|c|}{ Mother's specific concern - someone else's decision: } \\
\hline No & $153(92.7)$ & $37(94.9)$ & $116(92.1)$ \\
\hline Yes & $12(7.3)$ & $2(5.13)$ & $10(7.9)$ \\
\hline \multicolumn{4}{|c|}{ Mother's specific concern - too far to travel: } \\
\hline No & $147(89.1)$ & $36(92.3)$ & $111(88.1)$ \\
\hline Yes & $18(10.9)$ & $3(7.7)$ & $15(11.9)$ \\
\hline \multicolumn{4}{|c|}{ Mother's specific concern - no transport: } \\
\hline No & $161(97.6)$ & $38(97.4)$ & $123(97.6)$ \\
\hline Yes & $4(2.4)$ & $1(2.6)$ & $3(2.4)$ \\
\hline \multicolumn{4}{|c|}{ Mother's specific concern - thought needed traditional care: } \\
\hline No & $139(84.2)$ & $38(97.4)$ & $101(80.2)$ \\
\hline Yes & $26(15.8)$ & $1(2.6)$ & $25(19.8)$ \\
\hline \multicolumn{4}{|c|}{ Mother's specific concern - too sick to travel: } \\
\hline No & $151(91.5)$ & $38(97.4)$ & $113(89.7)$ \\
\hline Yes & $14(8.5)$ & $1(2.6)$ & $13(10.3)$ \\
\hline \multicolumn{4}{|c|}{ Mother's specific concern - thought would die anyway } \\
\hline No & $136(82.4)$ & $36(92.3)$ & $100(79.4)$ \\
\hline Yes & $29(17.6)$ & $3(7.7)$ & $26(20.6)$ \\
\hline \multicolumn{4}{|c|}{ Mother's specific concern - late at night: } \\
\hline No & $146(88.5)$ & $37(94.9)$ & $109(86.5)$ \\
\hline Yes & $19(11.5)$ & $2(5.13)$ & $17(13.5)$ \\
\hline
\end{tabular}

Mother's specific concern - not satisfied with service at formal health facility:

\begin{tabular}{|c|c|c|c|}
\hline No & $165(100)$ & $39(100)$ & $126(100)$ \\
\hline Yes & 0 & 0 & 0 \\
\hline \multicolumn{4}{|c|}{ Mother's specific concern - other reasons: } \\
\hline No & $157(95.2)$ & $38(97.4)$ & $119(94.4)$ \\
\hline Yes & $8(4.9)$ & $1(2.6)$ & $7(5.6)$ \\
\hline
\end{tabular}

and Ghana that found that lethargy is one of the few signs of neonatal illness that mothers both recognize and understand to indicate the need for formal health care [15-17]. These studies distinguished such signs from others that mothers recognized but took to mean that traditional or no care was required and other illness signs that were poorly recognized. Thus, the current study adds to the evidence suggesting that focusing health messages on a few well-recognized and intrinsically motivating illness signs may be more effective in increasing formal health care-seeking for sick neonates than a strategy that urges care-seeking for all danger signs.
Preterm babies had care sought for them at a lower rate than full-term neonates. We found that among the subset that reported barriers to seeking formal care, $24 \%$ of the mothers who had preterm babies thought the babies would die anyway while only 14\% of the mothers with full-term neonates felt that way. Thus, even though it is not possible to adjust for the reported barriers in the main model, it may be that being preterm led the mothers to think that there was no hope of survival.

We investigated whether those who were born at a health facility survived longer before illness onset and whether care-seeking decisions were different for them. The numbers that can be used to make any such inference were small. Of the total 331 participants, 25 were born at a facility. Of those 25, 15 (63\%) reported that illness began on day 1 of life, which is comparable to $66 \%$ of the homebirths. Furthermore, 17 (71\%) of the facility births sought formal care on the same day as illness onset, which is also comparable to the 228 (75\%) of home-births. Hence, we conclude that the small subset of facility births were not different in terms of their survival before illness onset, nor by the care-seeking decisions made for them.

Neonates who were delivered at home were less likely to have care sought for them. This was an expected finding because mothers who are less likely to seek care at facilities are also less likely to deliver there. In this Bangladesh cohort, the reported barriers to seeking care have also been found in similar low-income settings [10,11,22-25]. The main ones were the cost, having no hope of survival or believing that traditional care was more appropriate for some illnesses.

\section{Strengths and limitations}

The main strength of our study is that it was a comparative analysis of those caregivers who did vs those who did not seek formal care, accounting for competing risks of death or seeking informal care first. It thus allowed for a more definitive determination of the factors that constrain prompt formal health care-seeking fatally ill neonates. Data were collected by highly-trained and skilled female verbal autopsy interviewers working for the HFS and CHX studies as well as for the social autopsy component. Furthermore, this was a community-based study that included both home and hospital births, and thus it did not suffer selection bias that would occur if only hospital births had been included.

A limitation to our study is that there may have been bias in self-reported time to seeking care (days/h) given that the recall period was up to 2.5 years for some of the respondents.

Not all mothers responded to the questions of the specific barriers that prevented them from seeking care or that they 
had to overcome. Thus it was not possible to include responses to these barriers in the main multivariable model. However, these reported barriers have also been found to apply in other similar settings.

The time to care-seeking data was not presented in hours for all types of events and thus we were not able to fully describe the pattern of events for the first day of life which is a crucial time when most deaths and actions are taken on. Time in hours was only asked of those who sought care at a formal provider and thus we could not give a comparative analysis of the events.

\section{CONCLUSION}

Our analysis has shown that in this rural Bangladesh cohort, the majority of the neonates died before formal care could be sought for them, but when care was sought it was more likely to be formal vs informal care. There were economic and social belief barriers that delayed or prevented care-seeking. There is a need for programs that address such barriers and educate caregivers about danger signs that require formal health care and the importance of timely care-seeking, particularly for preterm neonates and those who deliver at home.

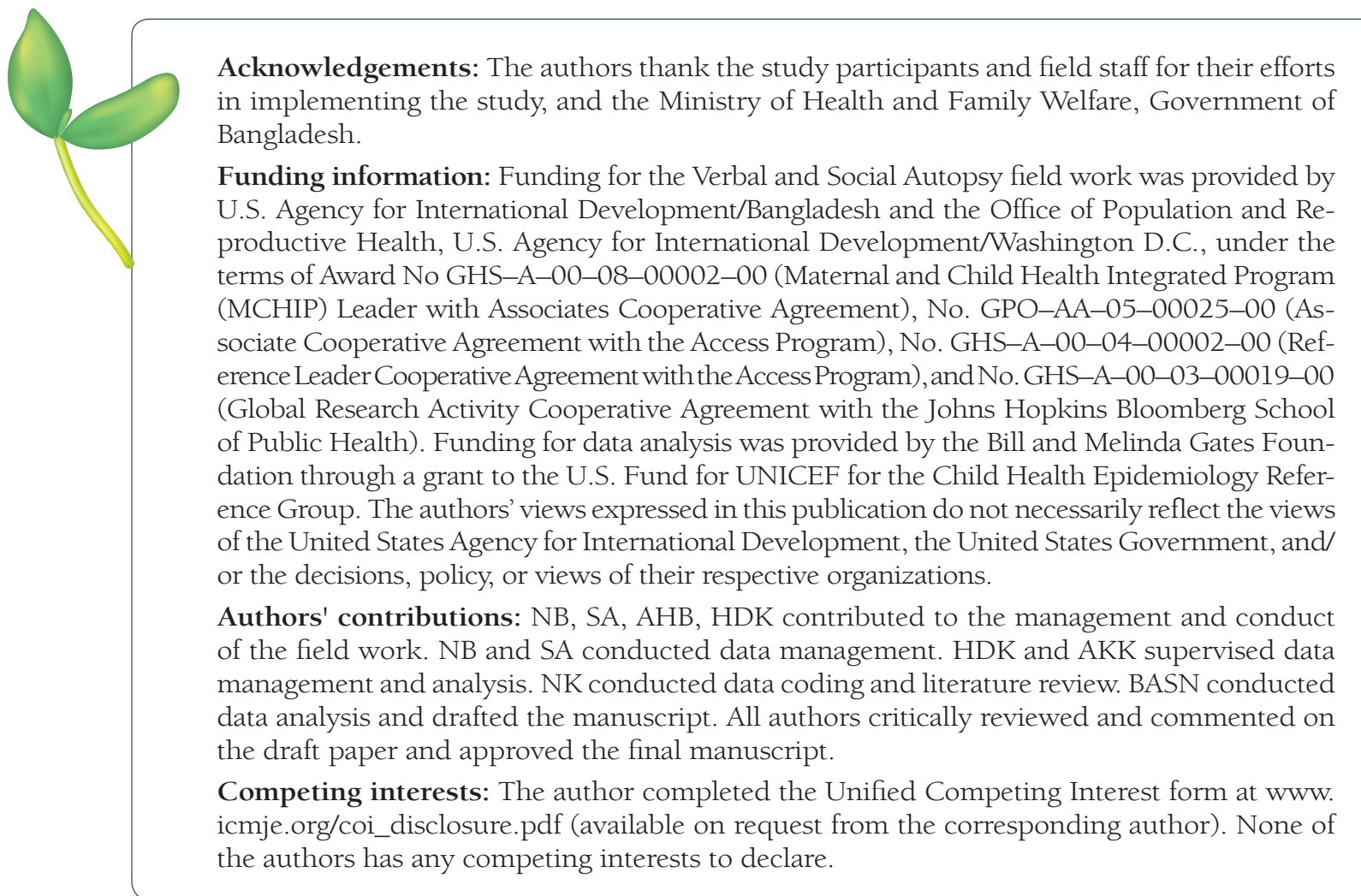

1 UN Inter-agency Group for Child Mortality. Child Mortality Estimates September 2014. Available at: http:// www.childmortality.org/. Accessed: 4 January 2016.

2 Lawn JE, Blencowe H, Oza S, You D, Lee AC, Waiswa P, et al. Every Newborn: progress, priorities, and potential beyond survival. Lancet. 2014;384:189-205. Medline:24853593 doi:10.1016/S0140-6736(14)60496-7

3 Black RE, Cousens S, Johnson HL, Lawn JE, Rudan I, Bassani DG, et al. Global, regional, and national causes of child mortality in 2008: a systematic analysis. Lancet. 2010;375:1969-87. Medline:20466419 doi:10.1016/ S0140-6736(10)60549-1

4 You D, Jones G, Hill K, Wardlaw T, Chopra M. Levels and trends in child mortality, 1990-2009. Lancet. 2010;376:931-3. Medline:20851244 doi:10.1016/S0140-6736(10)61429-8

5 UNICEF. Levels and trends in child mortality: report 2013. New York, 2013.

6 Lawn JE, Cousens S, Zupan J. 4 million neonatal deaths: when? Where? Why? Lancet. 2005;365:891-900. Medline:15752534 doi:10.1016/S0140-6736(05)71048-5

7 Liu L, Oza S, Hogan D, Perin J, Rudan I, Lawn JE, et al. Global, regional, and national causes of child mortality in 2000-13, with projections to inform post-2015 priorities: an updated systematic analysis. Lancet. 2015;385:430-40. Medline:25280870 doi:10.1016/S0140-6736(14)61698-6 
8 Herbert HK, Lee AC, Chandran A, Rudan I, Baqui AH. Care seeking for neonatal illness in low- and middleincome countries: a systematic review. PLoS Med. 2012;9:e1001183. Medline:22412355 doi:10.1371/journal. pmed.1001183

9 Thaddeus S, Maine D. Too far to walk: maternal mortality in context. Soc Sci Med. 1994;38:1091-110. Medline: 8042057

10 Källander K, Hildenwall H, Waiswa P, Galiwango E, Peterson S, Pariyo G. Delayed care seeking for fatal pneumonia in children aged under five years in Uganda: a case-series study. Bull World Health Organ. 2008;86:3328. Medline:18545734 doi:10.2471/BLT.07.049353

11 Waiswa P, Kallander K, Peterson S, Tomson G, Pariyo GW. Using the three delays model to understand why newborn babies die in eastern Uganda. Trop Med Int Health. 2010;15:964-72. Medline:20636527 doi:10.1111/ j.1365-3156.2010.02557.x

12 Samuelsen H, Tersbol BP, Mbuyita SS. Do health systems delay the treatment of poor children? A qualitative study of child deaths in rural Tanzania. BMC Health Serv Res. 2013;13:67. Medline:23421705 doi:10.1186/14726963-13-67

13 Upadhyay RP, Rai SK, Krishnan A. Using three delays model to understand the social factors responsible for neonatal deaths in rural Haryana, India. J Trop Pediatr. 2013;59:100-5. Medline:23174990 doi:10.1093/tropej/ fms060

14 Applying the Three Delays Model: improving access to care for newborns with danger signs. Save The Children, 2013. Available at: http://www.healthynewbornnetwork.org/hnn-content/uploads/Applying-the-three-delaysmodel_Final.pdf. Accessed: 4 January 2016.

15 Awasthi S, Srivastava NM, Pant S. Symptom-specific care-seeking behavior for sick neonates among urban poor in Lucknow, Northern India. J Perinatol. 2008;28 Suppl 2:S69-75. Medline:19057571 doi:10.1038/jp.2008.169

16 Hill Z, Kendall C, Arthur P, Kirkwood B, Adjei E. Recognizing childhood illnesses and their traditional explanations: exploring options for care-seeking interventions in the context of the IMCI strategy in rural Ghana. Trop Med Int Health. 2003;8:668-76. Medline:12828551 doi:10.1046/j.1365-3156.2003.01058.x

17 Mohan P, Iyengar SD, Agarwal K, Martines JC, Sen K. Care-seeking practices in rural Rajasthan: barriers and facilitating factors. J Perinatol. 2008;28 Suppl 2:S31-7. Medline:19057566 doi:10.1038/jp.2008.167

18 Sreeramareddy CT, Shankar RP, Sreekumaran BV, Subba SH, Joshi HS, Ramachandran U. Care seeking behaviour for childhood illness—a questionnaire survey in western Nepal. BMC Int Health Hum Rights. 2006;6:7. Medline:16719911 doi:10.1186/1472-698X-6-7

19 Syed U, Khadka N, Khan A, Wall S. Care-seeking practices in South Asia: using formative research to design program interventions to save newborn lives. J Perinatol. 2008;28 Suppl 2:S9-13. Medline:19057572 doi:10.1038/jp.2008.165

20 de Zoysa I, Bhandari N, Akhtari N, Bhan MK. Careseeking for illness in young infants in an urban slum in India. Soc Sci Med. 1998;47:2101-11. Medline:10075250 doi:10.1016/S0277-9536(98)00275-5

21 Ogunlesi TA, Ogunlesi FB. Family Socio-Demographic Factors and Maternal Obstetric Factors Influencing Appropriate Health-Care Seeking Behaviours for Newborn Jaundice in Sagamu, Nigeria. Matern Child Health J. 2012;16:677-84. Medline:21365297 doi:10.1007/s10995-011-0765-1

22 Assefa T, Belachew T, Tegegn A. Mothers' health care seeking behavior for childhood illnesses in Derra district, Northshoa zone, Oromia regional state, Ethiopia. Ethiopian Journal of Health Sciences. 2008;18:87-94.

23 Hildenwall H, Tomson G, Kaija J, Pariyo G, Peterson S. "I never had the money for blood testing"-caretakers' experiences of care-seeking for fatal childhood fevers in rural Uganda-a mixed methods study. BMC Int Health Hum Rights. 2008;8:12. Medline:19055738 doi:10.1186/1472-698X-8-12

24 Ogunlesi TA, Olanrewaju DM. Socio-demographic factors and appropriate health care-seeking behavior for childhood illnesses. J Trop Pediatr. 2010;56:379-85. Medline:20167633 doi:10.1093/tropej/fmq009

25 Terra de Souza AC, Peterson KE, Andrade FM, Gardner J, Ascherio A. Circumstances of post-neonatal deaths in Ceara, Northeast Brazil: mothers' health care-seeking behaviors during their infants' fatal illness. Soc Sci Med. 2000;51:1675-93. Medline:11072887 doi:10.1016/S0277-9536(00)00100-3

26 Bangladesh Demographic and Health Survey, 2011. Available at: http://pdf.usaid.gov/pdf_docs/pnady754.pdf. Accessed: 4 January 2016.

27 Ahmed S, Sobhan F, Islam A. Neonatal Morbidity and care-seeking behaviour in rural areas of Bangladesh. J Trop Pediatr. 2001;47:98-105. Medline:11336143 doi:10.1093/tropej/47.2.98

28 Das SK, Nasrin D, Ahmed S, Wu Y, Ferdous F, Farzana FD, et al. Health care-seeking behavior for childhood diarrhea in Mirzapur, rural Bangladesh. Am J Trop Med Hyg. 2013;89(Suppl):62-8. Medline:23629937 doi:10.4269/ajtmh.13-0107

29 Shah R, Mullany LC, Darmstadt GL, Talukder RR, Rahman SM, Mannan I, et al. Determinants and pattern of care seeking for preterm newborns in a rural Bangladeshi cohort. BMC Health Serv Res. 2014;14:417. Medline:25242278 doi:10.1186/1472-6963-14-417

30 Chowdhury HR, Thompson SC, Ali M, Alam N, Yunus M, Streatfield PK. Care seeking for fatal illness episodes in neonates: a population-based study in rural Bangladesh. BMC Pediatr. 2011;11:88. Medline:21999253 doi:10.1186/1471-2431-11-88

31 Murray CJ, Lopez AD, Black R, Ahuja R, Ali SM, Baqui A, et al. Population Health Metrics Research Consortium gold standard verbal autopsy validation study: design, implementation, and development of analysis datasets. Popul Health Metr. 2011;9:27. Medline:21816095 doi:10.1186/1478-7954-9-27 
32 Murray CJ, Lozano R, Flaxman AD, Serina P, Phillips D, Stewart A, et al. Using verbal autopsy to measure causes of death: the comparative performance of existing methods. BMC Med. 2014;12:5. Medline:24405531 doi:10.1186/1741-7015-12-5

33 Baqui AH, Black RE, Arifeen SE, Hill K, Mitra SN, al Sabir A. Causes of childhood deaths in Bangladesh: results of a nationwide verbal autopsy study. Bull World Health Organ. 1998;76:161-71. Medline:9648357

34 Baqui AH, Darmstadt GL, Williams EK, Kumar V, Kiran TU, Panwar D, et al. Rates, timing and causes of neonatal deaths in rural India: implications for neonatal health programmes. Bull World Health Organ. 2006;84:70613. Medline:17128340 doi:10.2471/BLT.05.026443

35 Engmann C, Garces A, Jehan I, Ditekemena J, Phiri M, Mazariegos M, et al. Causes of community stillbirths and early neonatal deaths in low-income countries using verbal autopsy: an International, Multicenter Study. J Perinatol. 2012;32:585-92. Medline:22076413 doi:10.1038/jp.2011.154

36 Kalter HD, Salgado R, Babille M, Koffi AK, Black RE. Social autopsy for maternal and child deaths: a comprehensive literature review to examine the concept and the development of the method. Popul Health Metr. 2011;9:45. Medline:21819605 doi:10.1186/1478-7954-9-45

37 Waiswa P, Kalter HD, Jakob R, Black RE, Social Autopsy Working Group. Increased use of social autopsy is needed to improve maternal, neonatal and child health programmes in low-income countries. Bull World Health Organ. 2012;90:403-A.

38 Kalter HD, Salgado R, Moulton LH, Nieto P, Contreras A, Egas ML, et al. Factors constraining adherence to referral advice for severely ill children managed by the Integrated Management of Childhood Illness approach in Imbabura Province, Ecuador. Acta Paediatr. 2003;92:103-10. Medline:12650309 doi:10.1111/j.1651-2227.2003. tb00478.x

39 Ahmed S, Norton M, Williams E, Ahmed S, Shah R, Begum N. Operations research to add postpartum family planning to maternal and neonatal health to improve birth spacing in Sylhet District, Bangladesh. Glob Health Sci Pract. 2013;1:262-76. Medline:25276538 doi:10.9745/GHSP-D-13-00002

40 Mullany LC, El Arifeen S, Winch PJ, Shah R, Mannan I, Rahman SM, et al. Impact of 4.0\% chlorhexidine cleansing of the umbilical cord on mortality and omphalitis among newborns of Sylhet, Bangladesh: design of a community-based cluster randomized trial. BMC Pediatr. 2009;9:67. Medline:19845951 doi:10.1186/1471-2431-9-67

41 World Health Organization. Standard neonatal verbal autopsy questionnaire, revised version. World Health Organization. Geneva, WHO, 2003.

42 CHERG Verbal and Social Autopsy Survey Tools and Information 2014. Available at: http://cherg.org/projects/ pathways.html\#socialautopsy. Accessed on: 4 January 2016.

43 Satagopan JM, Ben-Porat L, Berwick M, Robson M, Kutler D, Auerbach AD. A note on competing risks in survival data analysis. Br J Cancer. 2004;91:1229-35. Medline:15305188 doi:10.1038/sj.bjc.6602102

44 Coviello V, Bogess M. Cumulative incidence estimation in the presence of competing risks. Stata J. 2004;4:103-12. 45 Fine JP, Gray RJ. A proportional hazards model for the subdistribution of a competing risk. J Am Stat Assoc. 1999;94:496-509. doi:10.1080/01621459.1999.10474144

46 Cleves M, Gutierres RG, Gould W, Marchencko YV. An introduction to survival analysis using STATA. College Station, Texas: Stata Press Publication, StataCorp LP; 2010. 